\title{
O toque inefável de Deus na alma-da-alma: reflexões sobre a mística em Edith Stein
}

The ineffable touch of God in the soul-of-the-soul: Reflections

on Edith Stein's mystic

Clelia Peretti (iDa

\section{Resumo}

O presente artigo discute a mística em Edith Stein a partir da análise fenomenológica da experiência mística carmelina. Apresenta elementos de compreensão da busca da verdade e seu sentido. A mística em Edith Stein é existencial, relacional, encarnada e trinitária. A conversão ao cristianismo conduz a filósofa à compreensão do caminho fenomenológico, perpassado pelo pensamento de Tomás de Aquino que contribui no esclarecimento do conceito de Deus e do ser humano como pessoa, um ser livre aberto à transcendência. No seu itinerário investigativo estabelece uma conexão entre teologia e filosofia e entre saber e crer. A experiência mística é discutida como fenômeno religioso, que se dá no sujeito místico e se comunica por meio de símbolos ou testemunhos. Ela analisa este fenômeno a partir da experiência São João da Cruz e Teresa D'Ávila. A vivência mística pressupõe o conhecimento e a fé, é uma realidade própria, experienciada, vivida, testemunhada e documentada de encontro com Deus, Verbo divino Encarnado. A teologia mística tem seu ápice na Ciência da Cruz, vida vivida em conformidade com este símbolo. A experiência mística atravessa a complexa unidade de corpo, psique e alma e as complexas unidades de sentido das vivências. $A$ alma é o "lugar" da união mística e a Trindade é "lugar" da comunhão pela qual é possível ascender "para" Cristo, quando se está "em" Cristo. O caminho da mística é o encontro com Deus que, sendo o Amor eterno, apresenta-se como um fogo devorador.

\footnotetext{
a Pontifícia Universidade Católica do Paraná, Curitiba, PR, Brasil. Doutora Teologia, e-mail: clelia.peretti@pucpr.br
} 
"Deus é amor". Ser possuído por Deus, quando o espírito estiver preparado, é inflamarse em amor.

Palavras-chave: Edith Stein. Mística cristã. Conhecimento da alma. Fenomenologia.

\section{Abstract}

This article discusses the mystique in Edith Stein from the phenomenological analysis of the Carmelian mystical experience. It presents elements of understanding of the search for truth and its meaning. The mystique in Edith Stein is existential, relational, incarnate and Trinitarian. The conversion to Christianity leads the philosopher to understand the phenomenological path, pervaded by the thought of Thomas Aquinas who contributes to clarifying the concept of God and the human being as a person, a free being open to transcendence. In his investigative itinerary he establishes a connection between theology and philosophy and between knowing and believing. The mystical experience is discussed as a religious phenomenon, which occurs in the mystical subject and communicates by means of symbols or testimonies. It analyzes this phenomenon from the experience of John of the Cross and Teresa D'Ávila. The mystical experience presupposes knowledge and faith, it is a reality of its own, experienced, lived, witnessed and documented against the encounter with God, divine Word Incarnate. Mystical theology has its apex in the Science of the Cross, a life lived in accordance with this symbol. The mystical experience goes through the complex unit of body, blink and soul and the complex units of meaning of the experiences. The soul is the "place" of mystical union and the Trinity is the "place" of communion through which it is possible to ascend "to" Christ, when one is "in" Christ. The path of mystique is the encounter with God, who, being Love eternal, presents itself as a devouring fire. "God is love". To be possessed by God, when the spirit is ready, is to ignite in love.

Keywords: Edith Stein. Christian mystic. Knowledge of the soul. Phenomenology.

\section{Introdução}

A vida e os escritos de Edith Stein (1891-1942) sempre me fascinaram em minha carreira acadêmica e despertaram interesse pelo seu percurso intelectual e riqueza de suas investigações, mas, sobretudo, pela sua genialidade feminina em saber deixar-se guiar pela "busca da verdade" e nesta ressignificar suas vivências. Deste modo, objetiva-se refletir sobre a Mística em Edith Stein, como toque inefável de Deus na alma-da-alma, a partir da análise fenomenológica da experiência mística, sobretudo, carmelina. Edith Stein não apenas reflete sobre a experiência de grandes nomes cristãos como Dionísio, Agostinho, Teresa e João 
da Cruz, mas é, antes, uma realidade própria, vivida, testemunhada e documentada, sobretudo em seus escritos, que se constituem verdadeiros testemunhos de uma vida interior rica, radicada na fé e na experiência do abandono às mãos de Deus.

A experiência de conversão ao cristianismo aproxima Edith Stein ao estudo dos pensadores medievais, sobretudo, de Tomás de Aquino. "Ela se conecta, assim, ao renascimento tomasiano enraizado em uma nova atenção à herança filosófica da Idade Média" (STEIN, 2019b, p.21). A filosofia tomista oferecia naquele momento uma grande contribuição de argumento ao pensamento católico. Nesse sentido, Stein reconhece o aporte da fenomenologia para rever a questão da filosofia perene. Numa atitude de grande sensibilidade, dedica-se ao aprofundamento da teologia cristã unificando nesse estudo elementos da sua formação fenomenológica. Por esta via, Edith Stein depara-se efetivamente, com outro tipo de conhecimento, que, para ela, ultrapassa as possibilidades da filosofia. Durante esse percurso, Edith Stein compreendeu e experienciou aquilo que transcende as duas vias da filosofia e da metafisica que vai além do nível natural para o sobrenatural na fé.

Disso resulta que, a partir de sua conversão ao cristianismo, filosofia e teologia contribuem para esclarecer questões fundamentais sobre a pessoa humana. Desse modo, "filosofia e teologia, assim como experiência, integram-se nela em uma unidade que resulta muito difícil de se separar" (SANCHO FERMíN, 2019a, p. 17).

A visão de Deus de Tomás influencia, por sua vez, a própria visão de ser humano de Edith Stein, uma vez que este é compreendido numa totalidade em que alma, corpo, inteligência, vontade e espírito constituem uma integridade, uma unidade reveladora da grandeza humana, haja vista que o que define o ser humano é ser pessoa e, consequentemente, um ser livre (STEIN, 2019b) esse ocupa um lugar central nos escritos da filósofa cristã. Sancho Fermín reforça que, para Stein, "a pessoa unificada é uma pessoa espiritual que está numa livre posição, perante seu corpo, como também perante sua alma" (2019a, p. 20-21).

A partir dessas concepções sobre Deus e o ser humano herdadas de Tomás de Aquino, Stein passa a desenvolver uma filosofia que não tem medo de assumirse cristã. Ela insiste em sua trajetória intelectual na necessidade da relação entre 
a doutrina da fé e a filosofia. Ao seu ver, a metafísica deve estar relacionada com a verdade revelada, e a metafísica nasce do encontro da filosofia com a teologia. Edith Stein "percorre de novo, sistematicamente, o itinerário da especulação medieval" (ALES BELLO, 2000, p. 226). Mas, para a análise da experiência mística, assume a postura fenomenológica seguindo os critérios propostos por Husserl na análise da realidade. Sua intenção não foi de elaborar uma metafísica ou uma ontologia, partindo da verdade revelada, uma vez que ela conhecia bem a distinção entre filosofia e teologia. A filósofa buscava uma confirmação, isto é, "uma continuidade entre aquilo que a compreensão racional, do tipo filosófico ou científico, permite captar e os dados contidos na revelação" (ALES BELLO, 2000, p. 225). De fato, na sua investigação, é possível identificar como consegue utilizar "harmonicamente" duas fontes diferentes. Nos seus escritos, encontramos "uma conexão entre teologia e filosofia e entre saber e crer" (STEIN, 2013, p. 39).

\section{Edith Stein e o debate filosófico-cultural de sua época}

Segundo Ales Bello (2000, p. 228), Edith Stein preocupa-se em examinar a configuração histórica da experiência religiosa e seus testemunhos. Ela entra no debate cultural da época favorável a tal comparação. No contexto cultural francês, as discussões sobre a possibilidade de uma filosofia cristã eram notórias entre os filósofos Gilson e Maritain, os quais mostravam que, na "época medieval, não houvera só uma especulação filosófica ao lado da teologia, mas que justamente a revelação judeu-cristã permitia ampliar os limites do conhecimento humano e alcançar algumas verdades a partir das quais, em seguida, a reflexão teria seguido para um desenvolvimento autônomo. Por isso, na opinião desses pensadores, "a experiência religiosa, longe de ser um freio para a pesquisa racional, constitui antes um estímulo poderoso" (ALES BELLO, 2000, p. 228-229). Embora Edith Stein compartilhe as ideias dos filósofos franceses em referência ao pensamento medieval, ela avança, mostrando que a filosofia não parte de algumas verdades de fé para depois desenvolvê-las de forma racional como sustentava Gilson. De acordo com Ales Bello, 
a filosofia é o lugar da reflexão humana em que são "harmonizadas", pelo fato de se reconhecer uma conveniência razoável de fazer isso, investigações e experiências diferentes; é o lugar em que se estabelece uma continuidade entre as experiências religiosas, a sua sistematização teórica, ou seja, a teologia, e a pesquisa confiadas às capacidades intelectuais humanas, isto é, aquela que tradicionalmente é chamada de filosofia (2000, p. 229).

Além disso, "o problema da mística, colocado no grande depósito da espiritualidade: ascética e mística, torna-se, agora, uma ciência teológica e histórica ao mesmo tempo" (SECONDINI, 2013, s/p). Filósofos e teólogos não se recusam a se confrontarem com os testemunhos do passado. Desse confronto nascem propostas de avaliação construtivas ou de rejeição aos percursos concretos, históricos e experienciais rumo à vida cristã em plenitude e perfeição. Também nascem propostas de crítica, dando à mística uma importância cultural nova.

Edith Stein, analisando os testemunhos dos grandes místicos da Ordem Carmelitana, coloca-se na esteira de outros grandes pensadores da época, tais como "J. Baruzi, M. Blondel, H. Bergson, A. Stolz, A. Mager, E. Gilson, M. Menéndez y Pelayo e, mais recentemente, K. Rahner, H. U. von Balthasar, Y. Congar, H. de Lubac, J. Leclercq e Th. Merton" (SECONDINI, 2013, s/p). Pelo rigor teológico e científico e pelas indicações práticas para uma vivência em transformação, esses pensadores contribuíram para leituras diversificadas do sujeito que experimenta o fenômeno religioso também para forma das religiões estabelecidas e que se manifesta como uma experiência pessoal, subjetiva e transformadora.

Edith Stein considera a experiência mística de um ponto de vista fenomenológico, "uma realidade (Sache), isto é, uma questão que diz respeito, precisamente, ao sentido daquele tipo de experiência que é chamado mística" (ALES BELLO, 2000, p. 234), que se dá no sujeito místico que comunica sua experiência por meio de livros ou testemunhos dessa vivência. Por isso, ao buscar compreender esse fenômeno excepcional, a filósofa detém-se na análise da obra de dois grandes místicos, Santa Teresa D’Ávila e, especialmente, São João da Cruz. A mística em Edith Stein não é uma mera exploração intelectual, mas é antes de tudo uma profunda convergência entre pensamento e vida, entre filosofia e teologia, entre fé e contemplação. Em Edith Stein, sua biografia mistura-se aos 
seus escritos pois estes permitem compreender os momentos decisivos de sua existência na passagem de duas tradições culturais e religiosas: o judaísmo e o cristianismo. De tal modo, seus escritos refletem a experiência intersubjetiva de alguém que se abriu ao mistério do outro e de Deus, como fundamento último de toda a existência.

\section{Fundamentos filosóficos da experiência mística em Edith Stein}

Na seção anterior, apontamos para a abertura de Edith Stein à filosofia cristã, que tem como tarefa preparar o caminho da fé. Para Stein,

a filosofia cristã não é somente o nome para designar uma atitude espiritual do filósofo cristã, não só a designação do conjunto de doutrinas dos pensadores cristãos, mas significa, além disso, o ideal de um perfectum opus rationis que consegue abraçar em uma unidade o conjunto do que nos oferecem a razão natural e a revelação (STEIN, 2019a, p. 53).

Assim, para a filósofa, é a filosofia (e não a teologia) que tem necessidade de um complemento de conteúdo, a ela compete estabelecer a unidade de uma doutrina que englobe a totalidade (STEIN, 2019a, p. 53). Edith Stein realiza uma verdadeira conversão filosófica, que a conduz à raiz da filosofia cristã no encontro com o filósofo e teólogo Tomás de Aquino (ALES BELLO, 2014). Na obra Ser finito e Ser eterno, Edith afirma que: "Se existe, pois, segundo a convicção de São Tomás um caminho, e um campo de trabalho comum para todos os que buscam a verdade, é evidente também que para ele a ciência natural e a fé, a filosofia e a teologia não estão separadas uma das outras como se não houvesse nada em comum entre elas" (STEIN, 2019a, p. 40).

Um dos pontos fundamentais na obra Ser finito e Ser eterno é a aceitação do conhecimento natural frente ao conhecimento da fé. Tal afirmação ajuda-nos a entender o caminho que Edith Stein vai percorrendo, partindo de Tomás, passando por Dionísio até desembocar em Teresa D’Ávila e João da Cruz. Nesse caminho, ela incorpora, sobretudo, sua fenomenologia em diálogo com a filosofia tomista (STEIN, 2019b). Apesar de serem caminhos distintos em relação à verdade, Edith corrobora a ideia de que tanto a filosofia quanto a teologia 
possuem muitos elementos em comum. Segundo ela, "as ciências filosóficas [...] permanecem no âmbito da razão humana e, pelo contrário, a teologia 'repousa na revelação divina"' (STEIN, 2019a, p. 45).

Portanto, o caminho da filosofia cristã é o de preparar o acesso para a fé, porque a filosofia, enquanto busca da sabedoria, tende à fonte e à razão da sabedoria em si mesma. É necessário, todavia, considerar que a plenitude infinita da verdade divina não está encerrada na revelação. Um texto bastante significativo para a compreensão do conceito de mística em Stein encontra-se no capítulo 1, Introdução: A Questão do Ser, na obra Ser finito e Ser eterno:

\begin{abstract}
Deus se comunica ao espírito humano na medida e na forma que dita sua sabedoria. A ele corresponde ampliar a medida. A Ele corresponde apresentar a relação sob forma própria ao modo de pensar humano: a saber, como conhecimento progressivo passo a passo, sob forma de conceitos e juízos; o elevar o homem mais além de seu modo de pensar natural para um modo de conhecer completamente diferente, para uma ampliação da visão divina, que abraça tudo com um só olhar. A mais alta realização atingível por um espírito criado certamente não por suas próprias forças - é a 'visão beatífica', que Deus Ihe dá enquanto se une a Ele: o ser adquire participação do conhecimento divino vivendo a vida divina. A maior proximidade com esse fim supremo durante a vida terrena é a visão mística. Mas existe também um grau anterior no qual não é necessária essa suprema graça, quer dizer a fé autêntica e viva (STEIN, 2019a, p. 53-54).
\end{abstract}

A análise da experiência mística, em Stein, está fundamentalmente ligada à experiência de um conhecimento pleno, da realidade, de si mesma e de Deus. Essa pressupõe não apenas o desejo do conhecimento, mas também a fé, que aqui é entendida como uma percepção de Deus, para a qual a graça é extremamente necessária. Não podemos crer sem a graça. "E a graça é a participação na vida divina. Se nos abrimos à graça aceitando a fé, temos 'o começo da vida eterna em nós"' (STEIN, 2019a, p. 54). E, ainda, trata-se do “exercício vivo da virtude, o fato de crer (credere), ou o 'ato da fé'. É esse crer vital que nós contemplamos agora" (STEIN, 2019a, p. 54-55).

Sancho Fermín, ao analisar o conceito de mística em Edith Stein, resgata dois sentidos fundamentais para o termo: mística como experiência extraordinária do mistério e como vida radicada na união com Deus. Para Sancho Fermín, um dos grandes especialistas sobre a obra de Stein, existem dados mais que suficientes para afirmar que Edith Stein tenha passado por uma experiência 
mística extraordinária, antes mesmo de sua conversão. Contudo a mística, como vida radicada na união com Deus em Edith Stein, pode traduzir-se em quatro pontos: a) mística da dignidade do ser humano e da presença de Deus: Stein é testemunha de que a dignidade do homem tem seu fundamento somente em Deus; b) mística da visão da fé nos acontecimentos históricos: a filósofa consegue ler nos acontecimentos da sua vida sinais da ação de Deus na história; c) mística do diálogo e da unidade: a vida de Stein foi uma vida de diálogo: diálogo entre fenomenologia e filosofia tomista e também diálogo entre filosofia e mística; d) mística de um amor total, de entrega até o martírio, também conhecida como a mística da cruz (SANCHO FERMIN, 2019a, p. 66-67).

A seguir, aprofundar-se-ão os conceitos que fundamentam a mística steiniana e que têm o seu ápice na fenomenologia da Ciência da Cruz, em que Edith Stein caracteriza, como experiência mística, a experiência interpessoal de Deus como Outro. A mística steiniana encontra na Tradição da Igreja uma luz para a leitura de suas próprias experiências de Deus.

\section{A mística da alteridade na obra a Ciência da Cruz}

A análise fenomenológica realizada por Edith Stein da obra Scientia crucis, Estudo sobre São João da Cruz (2013), apresenta-se como um ótimo instrumento de compreensão e elucidação da experiência mística, que, embora se apresente como uma realidade excepcional, "não pode ser ignorada e de cuja análise é possível deduzir conotações essenciais" (ALES BELLO, 2000, p. 234). Na sua análise, Stein ao fundamentar o estudo da vida e da obra de João da Cruz a partir da teologia paulina, o faz tendo presente como horizonte de reflexão a experiência kénotica de Jesus Cristo. Ela recupera, na base do estudo de São João da Cruz, a vivência teológica e experiencial do mistério da Cruz. Assim, no centro da experiência mística está o encontro com a Cruz. Nesse sentido, a autora utiliza o método fenomenológico na análise dos símbolos para exprimir o encontro do eu finito com o Tu eterno, não por meio de conceitos, mas com uma linguagem que tem no símbolo a expressão máxima do indizível. tein é atraída pela experiência de que falam os escritos, ao ponto de apresentar-se uma experiência substancialmente inefável. Assim, a fenomenologia por ela utilizada 
orienta para uma total abertura para a experiência mística, como manifestação de Deus na alma e irrupção de Deus na história do ser humano. Para Stein, há uma estreita relação entre mística e sofrimento, pois a experiência de sofrimento e da cruz contribuem para dar explicação e valor ao mistério salvífico da cruz de Jesus.

Dessa forma, ela busca "compreender São João da Cruz na unidade de sua personalidade, tal como se manifesta em sua vida e obra" (STEIN, 2013, p. 7). Ela vê aí delineada a fisionomia do ser humano atual. $\mathrm{O}$ intento dela, portanto, não foi de apresentar uma biografia ou uma descrição dogmática completa, mas compreender, por meio dos escritos e testemunhos de vida do santo, as estruturas que regem a existência e a vida espiritual, colocando no centro de suas análises o eu, a liberdade e a pessoa. A possibilidade de tal fenômeno realizar-se explica-se pelo fato de se encontrar em São João da Cruz a atitude que caracteriza verdadeiramente os santos, isto é, "a receptividade interna e primária da alma, renascida pelo Espírito" (STEIN, 2013, p. 12).

Edith Stein define tal atitude com a palavra "realismo", por meio do qual entende a disponibilidade viva, dinâmica e pronta para aceitar tudo o que ocorrer de novo; tal abertura da alma é semelhante àquela das crianças que aceitam com simplicidade as impressões externas, reagindo a elas com alegria (STEIN, 2013, p. 13). A autora experimenta uma imersão na originalidade teológica da morte do Cristo via uma Ciência da Cruz, a qual investigou e aprofundou a partir dos pais espirituais carmelitas, numa experiência que atravessou seu espaço interior e que a conduziu a uma entrega radical resultante do seu seguimento a Cristo. Essa compreensão e experiência são atingidas por aqueles que acreditam no Caminho e no movimento de Jesus, o Cristo em relação com os demais no mundo. Somente aspira a cruz aqueles que tem abertos os olhos do espírito ao sentido sobrenatural dos acontecimentos do mundo. Portanto, no sofrimento humano, em nossos padeceres terrenais, quando nos unimos a Cristo, recebemos d'Ele a força suficiente para seguirmos em frente e superarmos gólgotas cotidianos da humanidade. Assim, quando a alma adulta assume uma disposição semelhante a respeito das verdades da fé, pode-se falar da capacidade de ela possuir um conhecimento, ou seja, uma ciência, que tem por objeto a Paixão, Morte e Ressurreição de Cristo, portanto, "a Ciência da Cruz", isto é, uma verdade já 
aceita, uma Teologia da Cruz" (STEIN, 2013, p. 11), ou seja, uma experiência mística que acontece no chão da humanidade e de seus dilemas.

Edith Stein reconhece, portanto, a experiência mística de São João da Cruz com base na experiência vivida pelo santo da Cruz e vê nos seus escritos "um caminho para quem quiser se introduzir no reino misterioso da vida interior" (STEIN, 2013, p. 37). Mas reconhece, também, que "João da Cruz não apresentou um tratado sistemático de mística propriamente dito", pois seu objetivo, ao escrever as obras, foi “conduzir pela mão" e completar, com os seus escritos, seu trabalho de guia espiritual das almas (STEIN, 2013, p. 37). Para isto, o santo toma por base a experiência apreendida da vida interior de outras almas, levando em conta a grande variedade de caminhos e a adaptação suave e flexível da graça às condições particulares de cada uma. Para João da Cruz, a Sagrada Escritura constitui a fonte viva para compreender a dinâmica da vida interior e a confirmação da própria experiência interior. A Sagrada Escritura torna transparente e possibilita o entendimento do "caminho da alma para Deus e a ação de Deus na alma" (STEIN, 2013, p. 38). E, ainda, "Deus criou as almas humanas para si. Ele quer uni-las a si e lhes dar a imensa plenitude e incalculável felicidade de sua própria vida — isso já nessa vida" (STEIN, 2013, p. 39). Mas o caminho para a vida interior exige coragem de aventurar-se nele. É um caminho estreito e íngreme. "A maioria se detém no meio da jornada; poucos passam das tentativas iniciais: pouquíssimas almas chegam ao objetivo final" (STEIN, 2013, p. 39).

Segundo Edith Stein, várias são as razões que impedem a alma de atingir a meta: os perigos do mundo, do inimigo maligno, da própria natureza humana, a ignorância e a falta de uma direção espiritual apropriada. As almas "não entendem o que nelas se passa, e raras vezes se encontra quem lhes possa abrir os olhos" (STEIN, 2013, p. 39). A essas almas, diz Edith Stein, São João da Cruz se coloca como guia, Ihes presta seu auxílio pois conhece todos os caminhos e atalhos da vida interior.

A possibilidade de exprimir tudo isso é potenciada em São João da Cruz à medida que ele revela também uma sensibilidade artística; o artista, de fato, é receptivo como uma criança e sabe representar uma imagem numa espécie de "revelação". Neste sentido, toda "produção artística [é], um mistério sagrado" e 
"uma forma de serviço divino" (STEIN, 2013, p. 14; ALES BELLO, 2000, p. 236-237). Todas essas qualidades estão presentes em João da Cruz: nele, "o artista, a criança e o santo se assemelham, [...] e se uniram para preparar as condições favoráveis à mensagem da cruz, que se transformaria em ciência da cruz" (STEIN, 2013, p. 13-14).

A disponibilidade da alma caracteriza, em geral, uma atitude de fé, mas o objetivo de Edith Stein é mostrar a peculiaridade da experiência mística que pressupõe, certamente, uma renúncia diante das coisas do mundo. Ao mesmo tempo, é a luta contra os sentidos, isto é, uma luta que é definida por São João da Cruz como a noite escura ativa, mas que se realiza somente na noite passiva, por meio da crucificação. Essa operação pode ser levada a término somente por Deus.

Na obra A Ciência da Cruz, há assim, uma grande contribuição fenomenológica de Edith Stein para a análise da experiência mística. Ao fundamentar o estudo da vida e da obra de João da Cruz, ela recupera a vivência teológica e experiencial do mistério da Cruz. A atenção de Edith volta-se para a experiência íntima da alma com o divino, seu abandono nas mãos de Deus. $A$ alma, nesta fase, é convidada a um ato de entrega, lançando-se com total confiança na procura de Deus na escuridão da fé: "Participará, então da contemplação mística lampejo na escuridão, sabedoria secreta de Deus, conhecimento obscuro e geral [geral lê-se genérico]: o único que condiz com o Deus incompreensível, o Deus que ofusca a razão e que the parece trevas" (STEIN, 2013, p. 103).

A característica da contemplação mística consiste em provocar uma espécie “'lampejo na escuridão', sabedoria secreta de Deus, conhecimento obscuro e geral: o único que condiz com o Deus incompreensível, o Deus que ofusca a razão e que lhe parece trevas" (STEIN, 2013, p. 103). Essa contemplação penetra a alma, e o fará tanto quanto mais livre a alma estiver de todas as impressões; é "delicada, espiritual, íntima e supratemporal”, porque é "um verdadeiro começo da vida eterna em nós”. Edith Stein quer ainda mostrar que não é uma simples aceitação da fé, [...], mas de um íntimo 'ser tocado por Deus e viver uma íntima experiência de Deus', o que tem força de desprende a alma de 
todas as coisas criadas, elevá-la e mergulhá-la em um amor que desconhece o objeto amado" (STEIN, 2013, p. 103).

Consequentemente, não se trata de um conhecimento intelectual, nem de uma adesão de fé, mas da "união transformante" e divinizante, que se realiza "através do amor perfeito" (STEIN, 2013, p. 139). Isso pode ser elucidado por meio da investigação das diversas formas de união com Deus.

Edith Stein vê, na obra Subida ao Monte Carmelo, de São João da Cruz, três formas de união com Deus: a primeira é a presença de Deus em todas as coisas que deste modo são preservadas no seu ser; a segunda é a inabitação de Deus na alma mediante a graça; a terceira consiste na união transformadora realizada através do amor (STEIN, 2019a, p. 139). Para Stein, trata-se apenas de uma diferença qualitativa, com que, segundo ela, também Santa Teresa concorda. De fato, a presença de Deus pela graça é diferente da presença divina comum a todas as demais criaturas e que a mantém na sua existência, como também é diferente da união que se realiza por meio do amor daquela que é efetuada pela graça (STEIN, 2019a, p. 140).

Convém ressaltar que não se encontra nos escritos de Edith Stein uma exposição completa sobre como se dão as modalidades de união, mas apenas uma descrição essencial do fenômeno da mística. Ela quer identificar os aspectos específicos e descobre, no Castelo Interior de Teresa D’Ávila, aquele estágio indicado como "oração de união" "que a Santa distingue com mais nitidez do que faz João quando fala da inabitação pela graça. Tal oração consiste no "arrebatamento da alma em Deus, que a torna completamente insensível às coisas do mundo e inteiramente atenta a Deus" (STEIN, 2013, p. 142). Neste arrebatamento, a alma fica privada de sentidos, tornando-se incapaz de pensar qualquer coisa ou ter consciência de algo, nem mesmo da experiência do amor. Esse estado dura um prazo de tempo limitado, durante o qual o que se experimenta supera todas as alegrias e uma felicidade que vai além da imaginação. Ao término desse estado de espírito, quando a alma recupera os

\footnotetext{
${ }^{1}$ Segundo Teresa D'Ávila, no Castelo Interior, $5^{a}$ morada, I. 10, a oração de quiete e de união advém "daquela verdade de Fé que nos ensina estar Deus presente em todas as coisas, por sua essência, sua potência e sua presença" (STEIN, 2013, p. 140, nota 186).
} 
sentidos, está bem consciente de ter permanecido em comunhão com Deus, e nem pode duvidar de ter vivido aquela experiência (STEIN, 2013, p. 142-143).

Deste modo, embora o núcleo da experiência mística seja o contato com Deus, sem palavras nem imagens, as imagens e palavras acabam impondo-se a nossa atividade de conhecimento, para, de um lado, permitir apresentar Deus da maneira mais próxima possível daquela como se o conheceu e, de outro, para permitir reconhecer se se trata realmente de Deus quando se depara com algum discurso sobre ele (STEIN, 2013, p. 56-59).

Assim, para Edith Stein, tanto Teresa D’Ávila quanto João da Cruz concordam na descrição deste último estágio de união com Deus, preparado certamente pela vontade humana, mas realizado além da mesma e, em todo caso, superando qualquer capacidade afetiva e intelectual. De tal modo, a entrega da vontade própria à vontade divina possibilita à alma "entregar-se a Deus em Deus". Por isso, diz Edith Stein,

há algo essencialmente diferente da simples união pela graça: aqui ocorre a mais íntima e profunda absorção pelo ser divino, que por sua vez deifica a alma. É uma união de pessoas que não suspende a independência pessoal, mas a pressupõe; é como uma mútua penetração, sobrepujada somente pela união das pessoas divinas, protótipo daquela (STEIN, 2013, p. 150).

Para Edith Stein a "união mística" deve ser distinta da fé, diferenciando-se uma da outra qualitativamente. A primeira pode ser concedida a um incrédulo para o despertar da fé e dispô-lo a receber a graça santificante, ao passo que a fé e o amor, por sua vez, apresentam-se certamente preparatórios a respeito da união mística: trata-se na verdade de "dois caminhos diversos e gradativos" (STEIN, 2013, p. 149). O que caracteriza o caminho da mística é o encontro com Deus que, sendo o Amor eterno, apresenta-se como um fogo devorador. "Deus é amor. Ser possuído por Deus, quando o espírito tiver preparado, é inflamar-se em amor. $\mathrm{O}$ amor eterno é fogo que devora tudo o que é finito, e finitos são os movimentos despertados na alma pelas criaturas" (STEIN, 2013, p. 153). Por isso, embora a alma queira afastar-se desse fogo, voltando-se para as coisas criadas, na realidade não pode fugir, porque: "o amor torna-se para ela o fogo devorador" (STEIN, 2013, p. 153). O exemplo mais importante da união mística é dado por Cristo que "[...] passou todos os instantes de sua vida em irrestrita entrega ao 
amor divino. Tomando sobre si o peso do pecado da humanidade, abraçou-o com amor misericordioso e o guardou em sua alma - foi o que fez em sua encarnação pelo 'Ecce venio"' (STEIN, 2013, p. 154). Deste modo, foi possível realizar a Redenção. "O 'consummatum est' é o anúncio do fim do holocausto expiatório; o 'Pater in manus tuas commendo spiritum meum' é a volta definitiva para a união de amor eterna e inalterável" (STEIN, 2013, p. 154).

Edith Stein evidencia, assim, no mistério pessoal da experiência mística cristã, a relação dinâmica e recíproca EU-TU e à sua verdade vivida, atuada e conhecida. Ela articula a experiência da presença da Alteridade pessoal, evidenciando as vivências subjacentes àquela experiência, indicando o movimento intencional da consciência, no rigor do método fenomenológico, legitimando na análise da Ciência da Cruz uma fundamentação filosóficoontológica da alteridade pessoal. $\mathrm{Na}$ análise da experiência mística, ela associa, de modo concreto, as complexas nuances ligadas à "via interior" de tipo agostiniano, ou seja, a experiência pessoal de interiorização da verdade ${ }^{2}$. Aborda um tipo de "vivência" que se articula com um "sentir". O "sentir o outro dentro de si”, é, de fato, o significado mais próprio da Einfühlung (STEIN, 1998; ALES BELLO, 2000; MANGANARO, 2000), que analisa a modalidade com a qual a alteridade pessoal apresenta-se a uma consciência que conhece e apreende o "tu" como alter-ego, outro, mas análogo a mim. Nessa mesma perspectiva, compreende-se a misteriosa adesão ao eterno, que se realiza no amor e "por" amor. Essa adesão é consentida ao Eu, em virtude da participação à vida íntima do Deus trinitário, que se multiplica em si, que quer ser também fora de si, e que transmite à alma humana um toque da Alteridade e da Eternidade que a habitam. Então, a alma conhece como é conhecida e, na medida em que conhece, ama assim como é amada, em um mútuo reforço de conhecimento e amor. "Assim, o

\footnotetext{
${ }^{2}$ A teoria agostiniana da iluminação nos faz pensar que a luz brilha a um só tempo na presença de Deus e no interior do ser humano. Dessa maneira, a verdade não se encontra nem nas coisas externas nem na razão humana. A verdade parece estar em lugar algum, ela é o próprio Deus que irradia nas mentes e capacidade o "olho do espírito, a ver e discernir entre o verdadeiro e o falso. Nas palavras de Agostinho, "sem um sujeito conhecedor, nada pode haver de verdadeiro". Nesse sentido, o conhecimento é o resultado tanto de um exercício de apuração dos nossos olhos interiores como da própria manifestação da verdade de Deus (AGOSTINHO, 1998, Solilóquios. I: III, 3).
} 
espírito criado que se ama a si mesmo se torna imagem de Deus". Mas, para amarse, deve conhecer-se. "Espírito, amor e conhecimento são três em um", e cada um, inteiramente em si e inteiramente no outro (STEIN, 2019a, p. 465). Conduzida pela leitura de Agostinho, a experiência fenomenológica da mística em Edith Stein, segundo Manganaro (2004, p. 12) tratará:

Do mistério abissal da alma: está "dentro" do ser humano e, todavia, está fundamentada em um Outro, que a transcende. Neste sentido, não é, certamente, possível colocar-se nas mãos de Deus, possuí-lo, aprendê-lo sem reservas; mas é possível encontrá-lo em uma experiência de relação pessoal recíproca, vivida e dinâmica.

A ênfase na experiência intersubjetiva do relacionar-se com Deus conduz a alma para o campo da concretude, do contato com o Amado, que não se torna algo etéreo e distante, mas próximo, pessoal, relacional. Na vivência mística da inabitação de Deus por meio da união amorosa, não há a exclusão da singularidade humana; não se trata de um panteísmo ou, ainda, de uma exclusão da vontade e personalidade humana, mas, antes, em configuração da vontade humana à vontade de Deus; não de imitação, mas de seguimento de Cristo, de tal forma que o indivíduo, por mais que entre no processo de aniquilamento e de kenosis, assim como Jesus, permanece um sujeito único e irrepetível.

A mística steiniana confirma não somente a possibilidade de encontro com Deus, como a sua necessidade. Trata-se de uma mística existencial, relacional porque tem no Outro o objeto do seu desejo —; em última análise, na fé cristã, refere-se à união esponsal. Essa união, segundo Manganaro, "é de fato a união de amor, a verdadeira scientia crucis", porque a alma reconhece estar diante de um conhecimento infundido, doado, um conhecimento atravessado pelo amor (MANGANARO, 2016, p. 94). Esse conhecimento, segundo Manganaro (2004), traduz-se em uma mística cuja experiência fontal é a Alteridade como Amor, alteridade da Trindade que se relaciona concretamente na alma através da pessoa de Jesus Cristo e do mistério da sua cruz. A expressão máxima dessa alteridade é descrita, pelos místicos, na forma do esponsalício ou matrimônio místico. 


\title{
A experiência mística como toque de Deus na alma
}

A experiência mística, na obra A Ciência da Cruz, aparece como consequência de um itinerário que tem na cruz o seu ponto de partida. A sabedoria mística é como que uma escada secreta, por onde, através da noite escura e do sofrimento, a alma recebe uma infusão de amor. É de fundamental importância a expressão infusão de amor, pois revela que a experiência de Deus, tanto em São João da Cruz como em Edith Stein, denota experimentar a Deus como Pessoa. Nesse sentido, o amor torna-se consequência de uma relação intersubjetiva. Tendo em si a efusão do amor, a alma descobre que pela sabedoria mística de Deus pode alcançar uma pequena luz:

\begin{abstract}
Por se tratar de coisas humanamente não-sabidas, é preciso ir ao seu encalço humanamente não sabendo e divinamente ignorando; porque, falando em linguagem mística... as coisas e perfeições divinas não são conhecidas e compreendidas enquanto as estamos procurando e exercitando, mas quando já foram encontradas e exercitadas... as sendas e pegadas em que Deus caminha na alma que deseja conduzir a si e distinguir com a união à sua sabedoria... Ele não quer que sejam reconhecidos (STEIN, 2013, p. 119).
\end{abstract}

Recorrendo à Noite Escura, Edith Stein resgata a sabedoria mística de Dionísio, do retorno místico da alma para Deus, imprimindo-lhe uma vivência intersubjetiva ao enfatizar a importância das marcas de Deus na alma. Por mais que a alma sinta essa presença e essa marca, o seu significado profundo a transcende, dado que Deus e sua experiência ultrapassam a linguagem humana. Por isso, a linguagem é sempre aproximativa, nunca conclusiva. Por mais que os místicos tentem exprimi-la por meio da poesia e da arte, ainda assim é falha, pois, ao tentar expor o seu real sentido, esbarra na sua própria contingência. O místico esbarra na insuficiência da linguagem: “O indizível só me poderá ser dado através do fracasso de minha linguagem. Só quando falha a construção, é que obtenho o que ela não conseguiu" (LISPECTOR, 2009, p. 179). Talvez seja essa a única forma discursiva de se falar de Deus e da sua experiência.

Tendo bem clara essa realidade, mais uma vez, exige-se do místico e daqueles que dele se aproximam uma sensibilidade ao metafórico e simbólico. É neste sentido que se pode falar em toque de Deus na alma. A experiência de Deus 
define-se, portanto, como algo específico da fé; logo, a experiência de Deus, cuja irrefutabilidade não se detém às categorias da razão, exige um método próprio. É necessário, portanto, superar a realidade fenomênica e buscar a transcendência da razão e a inviabilização da linguagem, cedendo espaço à própria experiência.

A expressão toque de Deus na alma pode ser entendida como uma certeza sobrenatural, infundida por Deus na alma do místico: "Esta segurança se apoia no sentimento de que Deus está presente e se sente tocado por Ele no mais profundo [...]. É o núcleo de toda vivência mística: o encontro com Deus de pessoa a pessoa" (STEIN, 2010, p. 101). A mística, em Stein, pressupõe e exige um relacionamento com o Outro, funda-se na relação intersubjetiva em que Deus manifesta seus dons e sua graça numa relação de doação de si mesmo. O fruto dessa experiência é a certeza de que, de alguma forma, muitas vezes não clara, Deus está presente. É um sentimento (no sentido etimológico de perceber com os sentidos) que Deus dá ao místico, como uma bússola, como um desejo que queima o coração e a mente e assegura ao ser humano, que faz a experiência de Deus, a certeza de não desistir jamais.

O sentimento da presença de Deus na alma assegura, apesar do seu caráter inefável, sua experiência como uma realidade objetiva e, portanto, "[...] é possível falar de Deus e da experiência de Deus, desde que com essa fala não se tenha a pretensão de esgotar todo o significado de seu objeto" (SAVIAN FILHO, 2000, p. 19). Esse é o grande desafio do místico: comunicar, além dos limites possíveis da sua fala, uma experiência original e transformante. $\mathrm{O}$ toque de Deus na alma carrega aquilo que Gregório de Nissa nomeia de percepção afetiva da Presença de Deus (ALTANER, STUIBER, 2003). Trata-se de mais do que conhecimento, ou seja, consiste em uma experiência em que a percepção afetiva da Presença de Deus é sentida e percebida com certo grau de certeza. Fenomenologicamente falando, essas manifestações extraordinárias são mais próprias da experiência mística que da própria religião cristã.

É preciso, portanto, levar em conta, sempre que possível, o conjunto da experiência, pois tal experiência faz-se possível, para os cristãos, por conta da própria iniciativa de Deus no mistério da encarnação e redenção na pessoa de Jesus Cristo. Sua encarnação, segundo Stein, é a condição maior de sofrimento. Pela redenção, ele curou aquilo que a árvore do paraíso havia tirado do ser 
humano. Com a redenção do Homem-Deus, abre-se novamente a toda a humanidade a possibilidade de se fazer homem novamente, em cada alma que pelo matrimônio místico a Ele se entrega (STEIN, 2013, p. 206). Deste modo, a alma já escapou da noite, aproxima-se dos segredos íntimos e tem a impressão de que cada erupção da chama do amor "é um início da vida eterna, porque o Espírito Santo, a eleva à atividade de Deus em Deus" (STEIN, 2013, p. 157). A alma, ao ser tomada pelo Espírito Santo, sente que “Deus investe sobre ela com ímpeto sobrenatural, elevando-a acima da carne e conduzindo-a à consumação almejada. Trata-se de verdadeiros encontros - O Espírito Santo penetra sua essência, transfigura-a e diviniza-a" (STEIN, 2013, p. 161).

É significativo que, quando Edith Stein mais se sentia acuada, perseguida, consternada pelo destino do seu povo, pôde escrever páginas tão belas sobre a relação de Deus com alma:

Na união nupcial, Deus cuida da alma com tanto amor que nem mesmo o mais terno amor de mãe lhe pode ser comparado. Ele lhe dá seu peito, quer dizer, revelaIhe seus segredos e lhe oferece a ciência deleitosa, que é a teologia mística, o conhecimento secreto de Deus. E a alma, por sua vez, se lhe entrega sem reservas: o que ela quer é ser toda dele para sempre, sem ter em si coisa alguma estranha a ele... Já que Deus a afastou de tudo aquilo a que seu coração poderá apegar-se, ela poderá entregar-se inteiramente a Deus, não em desejo, mas de fato (STEIN, 2013, p. 210).

Na delicadeza poética e simbólica de Edith Stein, parece haver, por vezes, uma revelação dos segredos mais profundos que experimenta a sua alma: Deus não é uma realidade distante, mas muito mais amoroso e cuidador que a melhor das mães. E como a mãe oferece o leite ao seu pequeno, assim Deus oferece $a$ ciência deleitosa que é a teologia mística. Ao afirmar que a teologia mística é constituída do deleite de Deus, Edith Stein parece afirmar que a mística que experimenta em sua vida, mesmo em meio as maiores perseguições, é a mística do cuidado. A mística do cuidado pode ser assim explicitada: Deus, como aquele que cuida do ser humano, que o conduz, que o sustenta, apesar da escuridão e da noite, e que, apesar dos sofrimentos e tormentas, introduz a humanidade nos mistérios ocultos de sua sabedoria e na perfeição do seu amor, pois a alma não tem outro exercício se não amar a Deus e "viver a vida de Deus e por isso se compraz no fogo de amor com que ele inflama as outras almas" (STEIN, 2013, p. 
191). Assim, a alma, penetrada da presença do Amado, canta as maravilhas que experimenta na união com ele e entra num estado de paz, delícia e doçura de amor. "Nos êxtases de amor, ela experimenta o que são Francisco procurava exprimir com as palavras 'meu Deus e meu tudo!'” (STEIN, 2013, p. 197). Como a brisa que sopra delicadamente as faces, o toque do ar pelo tato e o silvo do ar pela audição, assim também a alma experimenta e desfruta o toque das perfeições do Amado com o tato da alma. É, também, deste modo que as virtudes e graças do Amado são infundidas na alma (STEIN, 2013, p. 198). Desse modo, encontrar Deus, optar pelo seu projeto é tomar como fundamento o Verbo divino encarnado, Jesus, a Revelação do Logos. Em Edith Stein, o discurso e o caminho mais eficazes para se conhecer o Cristo são simplesmente o vivido e o contemplado. Disso resulta o calar, o silêncio de quem se coloca diante do Eterno indizível, mas que se sente tocado, em sua natureza finita por Ele. De fato, a teologia em Stein se alarga na compreensão daquilo que Cristo representará em seu existir. Todo o seu mistério ilumina sua vida para a plenitude. Ele tem uma incidência direta no progresso do campo vivencial-experiencial de transformação de Edith Stein. Em Cristo se vislumbra a nossa condição criatural de vida aberta à comunhão no espírito. Ele é Amor (1Jo 4,16), e o amor precisa de corporeidade para se revelar e experienciar. É no corpo de Cristo que se encerram todos os tesouros da sabedoria e do conhecimento ( $\mathrm{Col} 2,3)$. E, se o amor de Cristo pulsa no ser humano, então faz sentido ao ser viver como Ele viveu. De fato, a aproximação a Deus em sua filosofia espiritual se intensifica na Kénosis encarnatória. Daí sua devoção a Eucaristia.

\section{Considerações finais}

Edith Stein, nas análises fenomenológicas da mística carmelita, apresenta importantes contribuições para a compreensão da experiência mística cristã. Na esteira de santo Agostinho, toma a dimensão da interioridade como "sede" privilegiada da experiência da verdade, que, para ela, dá-se na relação recíproca e dinâmica entre interioridade, alteridade e transcendência. A interioridade está indissoluvelmente ligada à Alteridade, no dúplice sentido vertical e horizontal, ou melhor, na correlação entre o divino, o humano e o interpessoal. Assim, a 
experiência mística atravessa a complexa unidade de corpo, pisque e alma e as complexas unidades de sentido das vivências ${ }^{3}$. Edith Stein lê, assim, suas vivências e as dos santos da ordem carmelita, à luz da Cruz de Cristo e "debaixo da árvore da cruz", participando do sofrimento da morte e da própria redenção.

Emerge das análises da Ciência da Cruz, de São João da Cruz, o valor gnosiológico do viver e do sentir comunicado pelos místicos, articulado ao significado mais próprio da Einfühlung que é "sentir o outro dentro de si". Delineia-se, na análise fenomenológica dos escritos de São João da Cruz e de Teresa de Ávila, o sentido da linguagem simbólica, o realismo da experiência mística e o valor cognitivo da intencionalidade do encontro e do voltar-se da alma para o caminho que a conduz na direção do encontro ao TU eterno. Em Edith Stein, manifesta-se a distinção entre o subjetivo e o objetivo da experiência mística, bem como entre a fase "ativa" e "passiva" da mesma experiência. A vivência de abandono e de vazio é compreendida pela fenomenóloga como o passivo, a gratuidade a ser preenchida pelo poder de Deus, enfatizando assim que a origem da experiência pode até mesmo não resultar de maneira viva do próprio eu, mas provir de um Outro, de Deus. Altamente contemplativo e concentrado, na vivência do abandono, o eu experimenta seu vazio e, esvaziado, chega à raiz profunda de sua vivência: tal vazio constitui, na verdade, sua pureza mais cristalina. Não obstante o abandono, não há uma anulação ontológica: o eu é e continua livre e decide-se por Deus, sua vontade e seu desejo, despojados do egocentrismo, fundem-se na invocação.

Edith Stein faz referência à presença viva de Cristo na Eucaristia; não se trata de simples experiência de união, mas de uma verdadeira comunhão. Aqui é possível fornecer uma leitura ampla e contemporaneamente aprofundada da experiência heterocentrada naquela nós-centrada, pessoal e de inspiração trinitária. Na Ciência da Cruz, por exemplo, Edith Stein destaca a importância de

\footnotetext{
3 “Esta é uma expressão usual da fenomenologia. Com respeito à vivência, não se deve entender - como em algumas conexões na linguagem costumeira - algo especial, importante ou significativo, algo que impacta a alma em sua profundidade, mas simplesmente uma unidade de tempo que nasce da vida do eu". 'A unidade de vivência' é, portanto, "um todo que se constrói na vida consciente do eu em uma duração em que enche está última. Aqui não importa se se trata de um fazer livre ou de um acontecimento espontâneo, e qual seja, em geral, o conteúdo da vivência" (STEIN, 2019a, 71, § 4, nota 27).
} 
“ser Deus por participação", mencionado por São João da Cruz no vértice da “escada secreta". No estudo do Castelo interior dedicado à experiência mística de Santa Teresa de Ávila e significativamente inserido no apêndice do Ser finito e Ser eterno, Edith Stein reflete sobre a metáfora do castelo interior e define a união mística como transformação da alma vivente em um espírito doador de vida (STEIN, 2019a; MANGANARO, 2006).

A graça mística concede como experiência o que a fé ensina: a habitação de Deus na alma. Poderíamos dizer: a alma é o "lugar" da união mística, mas o "lugar" da comunhão mística é a Trindade, pela qual é possível ascender "para" Cristo, quando se está "em" Cristo. Acontece assim a passagem do "castelo interior" para o "castelo exterior"4: a alma não permanece estática ou inamovível imersa na contemplação de Deus; pelo contrário, deseja levar o amor experimentado para outras criaturas (CODA, 2006, p. 9-13). Trans-formada e trans-figurada pela união, com a força recebida conduz a sua ação no mundo, para todos e cada um, para o seu próximo. Em obediência ao novo mandamento de Cristo - "Amai-vos uns aos outros como Eu vos amei” (Jo 13,34) —, atua já nesta vida a comunhão com Deus Trindade — “Como tu, Pai, estás em mim e eu em ti, que também eles sejam um em nós" (Jo 17,21). Quando se sai do próprio eu, abandonando-se, só então se pode ser para-o-outro, se está com-o-outro como em si mesmo, no ritmo agostiniano do rede ipsum te, transcende te ipsum. O sentido próprio da experiência de Deus que é também o centro de qualquer experiência mística é o encontro com Deus de pessoa a pessoa. É o Deus Amor que se dá a conhecer à alma, que adere ao seu amor e decide permanecer em união com Ele, ainda, nesta vida.

\section{Referências}

AGOSTINHO. Solilóquios e a vida feliz. São Paulo: Paulus, 1998.

ALES BELLO, A. A Fenomenologia do Ser Humano: traços de uma filosofia no feminino. Trad. Antonio Angonese. Bauru: Edusc, 2000.

\footnotetext{
${ }^{4}$ A originária expressão de Chiara Lubich foi sabiamente retomada por CODA, Piero. La mistica trinitaria: dal castello interiore al castello esteriore (CODA, 2006, p. 9-13).
} 
ALES BELLO, A. Edith Stein: A Paixão pela Verdade. Trad. e rev. José Queiroz; rev. (org.) Márcio Luiz Fernandes, Clélia Peretti, Jacinta Turolo Garcia. Curitiba: Juruá, 2014.

ALTANER, B., STUIBER, A. Patrologia. Vida, obras e doutrina dos Padres da lgreja, Rio de Janeiro, Lumen Christi, 2003.

CODA, P. La mistica trinitaria: dal castello interiore al castello esteriore. In: MANGANARO, P. L'anima e il suo oltre: Ricerche sulla mistica cristiana. Roma: OCD, 2006.

BÍBLIA. A Bíblia de Jerusalém. Nova edição rev. e ampl. São Paulo: Paulus, 2015.

PSEUDO-DIONÍSIO, O Areopagita. Obra Completa. Trad. Roque Aparecido Frangiotti. São Paulo: Paulus, 2004.

SANCHO FIRMIN, J. Introdução. In: STEIN, E. Ser finito e ser eterno. Coord. João Ricardo Moderno; trad. Zaíra Célia Crepaldi. Rio de Janeiro: Forense Universitária, 2019a.

SANCHO FERMIN, J. Introdução Geral. In: STEIN, E. Obras Completas I: Escritos autobiográficos e Cartas. Madrid: Ed. Monte Carmelo, 2002.

SECONDINI, Bruno. A mística no século XX: Teorias e experiencias. A presença de São João da Cruz. Disponível em: https://mensagensdofreipetroniodemiranda.blogspot.com/ 2013/08/a-mistica-no-seculo-xx-teorias-e.html. Acesso em: 24 março 2021.

LISPECTOR, C. A Paixão segundo G.H. Rio de Janeiro: Rocco, 2009.

MANGANARO, Patrizia. L'anima e il suo oltre. Ricerche sulla mistica cristiana. Roma: OCD, 2000.

MANGANARO, P. Verso l'Altro: l'esperienza mistica tra interiorità e trascendenza. Roma: Città Nuova, 2002.

MANGANARO, P. Alteridade, filosofia, mística: entre fenomenologia e epistemologia. Memorandum, v. 6, p. 3-24, 2004. Disponível em: http://www.fafich.ufmg.br/ memorandum/artigos06/manganaro01.htm. Acesso em: 22 mar. 2020.

MANGANARO, P. Fenomenologia da Relação: A pessoa humana em Edith Stein. Trad. Clélia Peretti. Curitiba: Juruá, 2016.

SAVIAN FILHO, J. O toque do inefável: Apontamentos sobre a experiência mística de Deus em Edith Stein. Bauru: Edusc, 2000.

STEIN, E. Vida de uma família judia e outros escritos autobiográficos. Trad. Maria do Carmo Ventura Wollny, Renato Kirchner; rev. técn. Juvenal Savian Filho. São Paulo: Paulus, 2018.

STEIN, E. Ser finito e Ser eterno. Coord. João Ricardo Moderno; trad. Zaíra Célia Crepaldi. Rio de Janeiro: Forense Universitária, 2019a. 
STEIN, E. A Ciência da Cruz: Estudo sobre São João da Cruz. Trad. D. Beda Kruse. 7. ed. São Paulo: Loyola, 2013.

STEIN, E. Caminos del conocimiento de Dios. La teología simbólica del Areopagita y sus supuestos prácticos. In: STEIN, E. Escritos Espirituales. Trad. Francisco Javier Sancho Fermín. Madrid: Biblioteca de Autores Cristianos, 2010.

STEIN, E. Il problema dell'empatia. 2. ed. Trad. E. Costantini, E. Schulze-Costantini. Roma: Studium, 1998.

STEIN, E. Edith Stein: Texto sobre Husserl e Tomas de Aquino. Trad. De Ursula Anne Matthias... [et.] revisão da trad. e revisão técnica de Juvenal Savian Filho. São Paulo: Paulus, 2019b.

TUROLDO GARCIA, A. J; ALES BELLO, A. In: STEIN, E. Vida de uma família judia e outros escritos autobiográficos. Trad. Maria do Carmo Ventura Wollny, Renato Kirchner; rev. técn. Juvenal Savian Filho. São Paulo: Paulus, 2018. 